\title{
One hundred years of neurosurgery: contributions of American women
}

\author{
Jacquelyn Corley, MD,, 2 Eliana Kim, BS, ${ }^{1,3}$ Chris Ann Philips, BS, ${ }^{4}$ Martina Stippler, MD, ${ }^{5}$ \\ Ann M. Parr, MD, PhD, ${ }^{6}$ Jennifer Sweet, MD, ${ }^{7}$ and Gail Rosseau, MD ${ }^{1,8}$
}

\begin{abstract}
${ }^{1}$ Gender Equity Initiative in Global Surgery, Boston, Massachusetts; ${ }^{2}$ Department of Neurological Surgery, Duke University Hospital, Durham, North Carolina; ${ }^{3}$ University of California, San Francisco School of Medicine, San Francisco, California; ${ }^{4}$ American Association of Neurological Surgeons, Rolling Meadows, Illinois; ${ }^{5}$ Department of Neurosurgery, Beth Israel Deaconess Medical Center, Boston, Massachusetts; ${ }^{6}$ Department of Neurosurgery, University of Minnesota, Minneapolis, Minnesota; 'Department of Neurosurgery, Case Western Reserve University, Cleveland, Ohio; and ${ }^{8}$ Department of Neurosurgery, George Washington University School of Medicine and Health Sciences, Washington, DC
\end{abstract}

\begin{abstract}
The end of the first 100 years of any endeavor is an appropriate time to look back and peer forward. As neurosurgery celebrates its 1 st century as a specialty, the increasing role of women neurosurgeons is a major theme. This article documents the early women pioneers in neurosurgery. The contributions of these trailblazers to the origins, academics, and professional organizations of neurosurgery are highlighted. The formation of Women in Neurosurgery in 1989 is described, as is the important role this organization has played in introducing and promoting talented women in the profession. Contributions of women neurosurgeons to academic medicine and society as a whole are briefly highlighted. Contemporary efforts and initiatives indicate future directions in which women may lead neurosurgery in its 2nd century. https://thejns.org/doi/abs/10.3171/2019.12.JNS192878
\end{abstract}

KEYWORDS Women in Neurosurgery; WINS; gender; glass ceiling; American Association of Neurological Surgeons; AANS; Congress of Neurological Surgeons; CNS; Neurosurgical Society of America; NSA; Society of Neurological Surgeons; SNS; history

$\mathrm{O}$ NE hundred years ago, in 1919, Dr. Harvey Cushing delivered an address to the American College of Surgeons on his experience with brain tumors, which, it should be noted, would have been greatly hindered without his associate Dr. Louise Eisenhardt. Upon completion of the speech it is said that the chairman, Dr. William J. Mayo, rose from his seat and declared, "Gentlemen, we have this day witnessed the birth of a new specialty, Neurological Surgery." ${ }^{3,24}$ This historical moment garnered the much-needed momentum to create a new professional organization, the Society of Neurological Surgeons (SNS). Commonly called "The Senior Society," it is now the oldest neurosurgical professional society in the world and its members comprise the contemporary leaders in the field. The Senior Society continues to play an active leadership role in coordinating other major neurosurgical organizations and regulating resident education. ${ }^{24}$
Indeed, the profession has flourished over the last century. Neurosurgery has been advanced by visionaries and pioneers who expanded practice from traditional specialties such as neurooncology, trauma, and degenerative spine to new fields including radiotherapy, functional neurosurgery, and spinal deformity correction. Most notably, neurosurgery has been defined by the caliber of character among neurosurgeons, who value quality patient care above all and revere the profound responsibility that is inherent within our practice.

Men have traditionally dominated the field, but there have been organized and systematic efforts to recruit more women to the workforce. ${ }^{1,4,7,9,11,14}$ It should be recognized that women have had increasing presence and responsibility in neurosurgery. By paving the way for today's female neurosurgeons and diversifying the workforce, a host of women have made noteworthy contributions. Their

ABBREVIATIONS AANS = American Association of Neurological Surgeons; ABNS = American Board of Neurological Surgery; AMA = American Medical Association; CNS = Congress of Neurological Surgeons; SNS = Society of Neurological Surgeons; WINS = Women in Neurosurgery.

SUBMITTED October 22, 2019. ACCEPTED December 3, 2019.

INCLUDE WHEN CITING Published online February 14, 2020; DOI: 10.3171/2019.12.JNS192878. 
achievements enrich neurosurgery and invite the best and brightest students of all backgrounds to pursue careers in neurosurgery. The purpose of this communication is to chronicle these trailblazing individuals, document their role in neurosurgery's bright history, and highlight the new and emerging initiatives that now exist for women in neurosurgery.

\section{Present From the Beginning}

Many women have played key roles in the progress of neurological surgery, but no account of American neurosurgical origins would be complete without consideration of Dr. Louise Eisenhardt. If Harvey Cushing is regarded as the founder of modern neurosurgery, Louise Eisenhardt was his right hand. Their collaboration began in 1915, when she worked as his editorial assistant, and continued while she pursued her medical degree at Tufts University School of Medicine. Although not a neurosurgeon, she was the first woman to become a neuropathologist and was Cushing's surgery associate from 1928 to 1934, making on-the-spot diagnoses of tumors as they were being removed by Dr. Cushing. While actively pursuing this busy clinical practice, she kept a cumulative case log, made exhaustive efforts to obtain follow-up on patients to provide accurate outcome data, coauthored landmark papers with Cushing, and taught neuropathology at Tufts. ${ }^{12}$ She became the first editor of the Journal of Neurosurgery and held this position from 1944 to 1965, continually elevating the standards of academic literature. She also served as the first woman president of the American Association of Neurological Surgeons (AANS), known at that time as the Harvey Cushing Society ${ }^{8}$ (see Figs. 1 and 2).

\section{Women as Neurosurgeons}

It was a number of years, however, before women became neurosurgeons. Dr. James Bean describes many prejudices and obstacles for women who choose to pursue the field of neurosurgery. He states: "We cannot afford the failure to attract the brightest and most talented in the applicant pool when they are excluded by subtle and deniable discrimination."' Other authors have substantiated this claim and detail direct and indirect prejudices and gender-based discrimination that have created barriers to success. ${ }^{1,5-7,9,11,14}$ Indeed, many women have had to overcome these hurdles. One such woman, Dr. Ruth Kerr Jakoby, attended Columbia University College of Physicians and Surgeons, then completed a neurosurgical residency in 1959 at George Washington University, where Hugo V. Rizzoli was chairman. ${ }^{21}$ In 1961 she became the first female diplomate of the American Board of Neurological Surgery (ABNS). She was elected president of the Washington Academy of Neurosurgery in 1972, planning and overseeing continuing neurosurgical education opportunities for fellow neurosurgeons in the nation's capital. ${ }^{25}$

Dr. Joan Venes (1935-2010), the first woman neurosurgery resident at Yale and the third female diplomate of the ABNS in 1974, was the first woman to be awarded the Van Wagenen Fellowship. Dr. Venes was a pioneer who helped develop pediatric neurosurgery as a subspecialty. She was one of the founding members of the American Society of
Pediatric Neurosurgery (ASPN) and the first chairwoman of the Pediatric Section of the AANS. In 1990 she was the first woman to be appointed professor of neurosurgery at the University of Michigan (see Fig. 3).

In 1977, Dr. Frances Conley, after having completed residency training at Stanford, became the fifth woman to become board certified in neurosurgery. In 1988, she was appointed professor of neurosurgery at the Stanford School of Medicine, and she became the first tenured female professor in neurosurgery in the US. ${ }^{2}$ Dr. Conley was also the first woman division chief of neurosurgery at the Palo Alto Veterans Affairs Hospital.

The field of neurosurgery celebrated a historic milestone in 1981 when Dr. Alexa Canady became the first African American female neurosurgeon. She received her MD from the University of Michigan in 1975, graduated with cum laude distinction, and was elected into the Alpha Omega Alpha Medical Honor Society. She then completed her neurosurgical residency training at the University of Minnesota, followed by a fellowship in pediatric neurosurgery at the Children's Hospital of Philadelphia. ${ }^{15}$ Dr. Canady continued a productive career as a neurosurgeon, excelling in research, leadership, and mentorship. Her accomplishments particularly inspired many women and people of color toward neurosurgery careers.

In 1982, Dr. M. Deborah Hyde became the second African American woman to become board certified by the ABNS. In 1977, she graduated from the Case Western Reserve University School of Medicine; she, too, was also elected into the Alpha Omega Alpha Society. She went on to complete her neurosurgical residency training at Case Western and has had a distinguished career in private practice. She has been active in philanthropy, establishing the Beacon of Hope Scholarship Foundation in 1991 to provide underprivileged African American high school students of Mississippi and south central Los Angeles with financial assistance for higher education. ${ }^{16}$

In 2018, Dr. Odette Harris became the first African American woman to be named a tenured professor of neurosurgery at Stanford University.

\section{Women in Neurosurgery}

In 1989, a group of 8 women met at a neurosurgery meeting in Atlanta, all noting that this was the first time they had seen other women at a professional meeting. Their conversations that day led to the creation of the organization Women in Neurosurgery (WINS). WINS was established with the mission to "educate, inspire, and encourage women neurosurgeons to realize their professional and personal goals, and to serve neurosurgery in addressing the issues inherent to training and maintaining a diverse and balanced workforce."3

In the early years of WINS, there were so few women in the field that the exhibit floor at national meetings featured a map with the names and locations of every woman in neurosurgery. Dr. Deborah Benzil was the first to serve as president of the organization. WINS joined other affiliated neurosurgical groups by becoming a Joint Section of the AANS and Congress of Neurological Surgeons (CNS) in 2014. Many other outstanding, trailblazing women fol- 
lowed as leaders of the organization (Supplemental Table 1), adding incorporation, governance structure, outreach, communication, and scholarship-all elements that strengthened and expanded the organization. For 30 years, WINS has been providing valuable leadership training for individuals and groups of women neurosurgeons, from which all of neurosurgery has benefited.

WINS membership has grown dramatically and now includes members in Asia, Europe, South America, and Africa. To date, members of WINS are active leaders within the neurosurgery community and are involved in many other professional societies within organized neurosurgery.

\section{Women in Organized Neurosurgery}

Women have celebrated many additional noteworthy achievements. In 1991, Dr. Carole Miller was the first woman elected president of the Neurosurgical Society of America (NSA). She spoke for many women in the profession when she said, "It never occurred to me I couldn't be a neurosurgeon." ${ }^{26}$ Dr. Deborah Benzil was the first woman to chair the Council of State Neurosurgical Societies, in 2014. Dr. Edie Zusman served on the AANS Board of Directors as regional director from 2005 to 2008, and Dr. Gail Rosseau was the second woman elected to the Board of Directors-and became the first woman officer when serving as vice president in 2015-2016. Dr. Linda Sternau was the first woman to serve on the executive board of the CNS. Dr. Jamie Ullman served the CNS as vice president, and was honored with their Distinguished Service Award in 2018. There are notable women leaders at the forefront of advancing the field of neurosurgery in new and creative directions: Dr. Edie Zusman is a nationally recognized expert on health systems and has devised new models for healthcare; Dr. Isabella Germano is an expert in cuttingedge technological innovations for brain tumor surgery. In April 2018, Dr. Shelly Timmons broke through a glass ceiling and was elected as the first female neurosurgeon to become president of the AANS. ${ }^{1}$

\section{Women in Academic Neurosurgery}

Since the specialty began, women have been integral to the progress of neurosurgical leadership and education. In 2005, Dr. Karin Muraszko, a pediatric neurosurgeon at the University of Michigan, was the first woman to be appointed chair of a department of neurosurgery in the US. ${ }^{25}$ Additionally, she became the first woman president of the SNS on the occasion of its 100th anniversary.

Additional women department chairs have recently been appointed. In 2017, Dr. Linda Liau became the chair of the neurosurgery department at the David Geffen School of Medicine at the University of California, Los Angeles. ${ }^{13}$ In 2018, Dr. Aviva Abosch was appointed chair of the Department of Neurosurgery at the University of Nebraska Medical Center College of Medicine, and in 2019 Dr. Shelly Timmons was appointed chair of the Department of Neurosurgery at Indiana University. Other women chiefs and chairwomen include Dr. Susan Durham, who served as division chief of the Department of Neurosurgery at the University of Vermont Medical Cen-

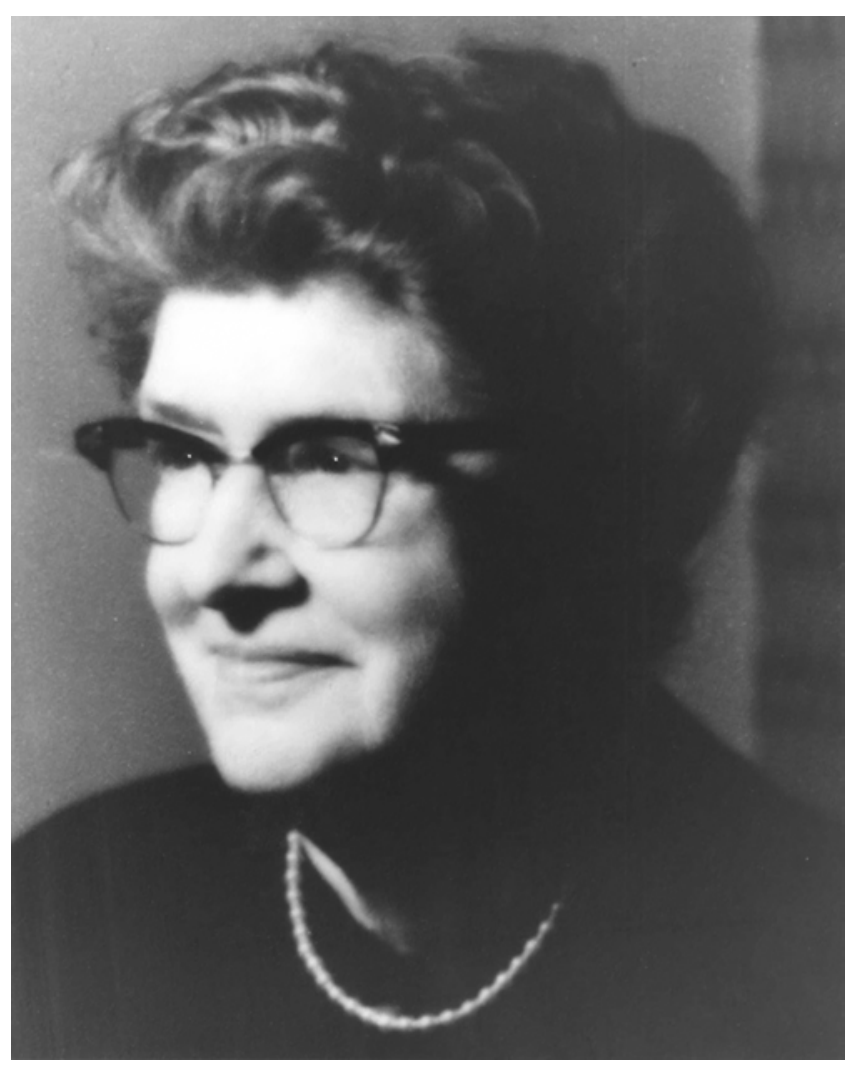

FIG. 1. Louise Eisenhardt circa 1939. Copyright Chris Philips. Published with permission.

ter; Dr. Sherry Taylor, who served as division chief for the Department of Neurosurgery at Baystate Medical Center; and Dr. Edie Zusman, who served as chief of neurosurgery at North Bay Medical Center.

\section{Women Neurosurgeons in Medical Leadership Outside Neurosurgery}

In 2018, Dr. Linda Liau's contributions to healthcare and science were cited when she was named to the $\mathrm{Na}$ tional Academy of Medicine. The membership is one of the highest honors a physician can achieve, and is reserved for those who have demonstrated outstanding professional achievements, commitment to service, and contributions to science, medicine, and public health.

A number of other women have represented neurosurgery well by serving other medical organizations: Dr. Maya Babu served on the Board of Trustees of the American Medical Association (AMA); ${ }^{14}$ Dr. Krystal Tomei received the AMA Excellence in Medicine Award $;{ }^{10}$ and Dr. Gail Rosseau chairs the Liaison Committee of the World Federation of Neurosurgical Societies (WFNS) and the $\mathrm{WHO}^{20}$

\section{Women Neurosurgeons in Leadership in Contemporary Society}

Quite a large number of women have served in multiple roles as the first woman in a given position, and doz- 


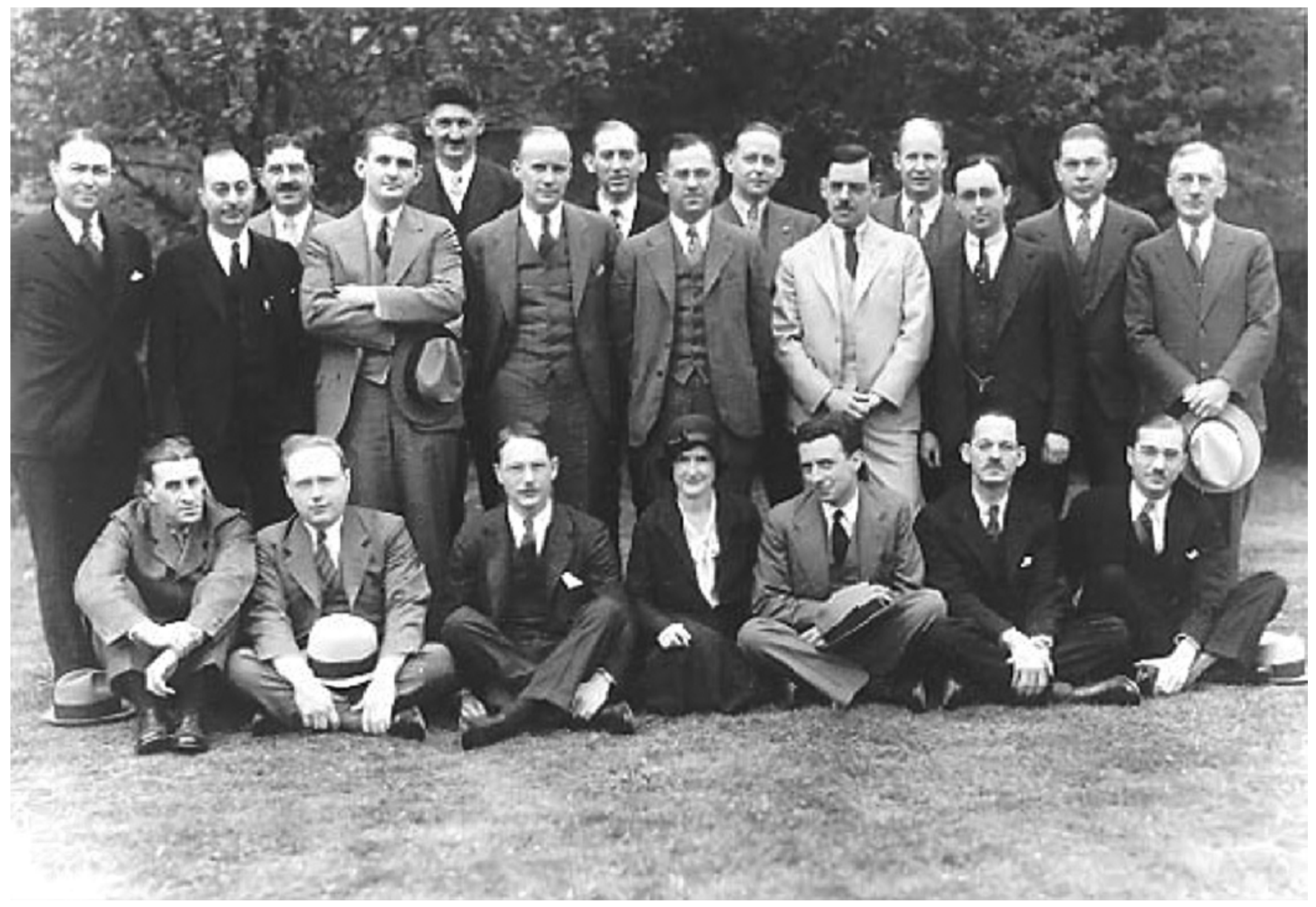

FIG. 2. Louise Eisenhardt front and center at the Harvey Cushing Society (1932). Copyright Chris Philips. Published with permission.

ens more women neurosurgeons have served as the first woman in a variety of leadership positions outside of neurosurgery.

The earliest women neurosurgeons were real trailblazers. Dr. Ruth Jakoby became a lawyer, receiving her JD in 1986. She became acting dean of the Antioch School of Law in 1989, where her special interests include antitrust issues and mergers of medical, legal, and educational institutions. ${ }^{21,22}$

Dr. Merylee Werthan was the second woman diplomate of the ABNS. She was the founder of the first all-female neurosurgical practice.

Dr. Monica Wehby was the Republican nominee for the US Senate from Oregon in the 2014 election. She lost to the Democratic incumbent, Jeff Merkley. Her political career was informed by her service on the AMA's board of trustees.

Dr. Kathryn Ko completed her training at Mt. Sinai Medical Center and received her MFA in 2012. She served as the inaugural artist in residence for the American Medical Women's Association. Her studio is in New York City. ${ }^{23}$

Women neurosurgeons have published books for the general public about their experiences in neurosurgery.
Dr. Frances Conley famously resigned her tenured position at Stanford University in protest of sexism in her department, chronicling the events in her 1998 memoir, Walking Out on the Boys. ${ }^{6,19}$ Dr. Katrina Firlik described her experience as a neurosurgery resident at the University of Pittsburgh in her 2006 book, Another Day in the Frontal Lobe. ${ }^{11}$

\section{The Next 100 Years}

Currently, women students outnumber men enrolled in American medical schools. Yet, women make up only $16.3 \%$ of neurosurgical residents and $6.1 \%$ of boardcertified neurosurgeons. ${ }^{3,18}$ Many women have identified obstacles to entry and success in neurosurgical practice, such as lack of mentorship and role models, systemic barriers that make pregnancy and child-rearing difficult or impossible, and frequent sexism among colleagues and patients. . $^{1-8,26,11,14}$ These injustices affect women of color the most; underrepresentation, institutional bias, and daily microaggressions rooted in both sexism and racism are compounded in their paths.

New studies have been conducted with a gender-based focus to track career paths of women in neurosurgery. 


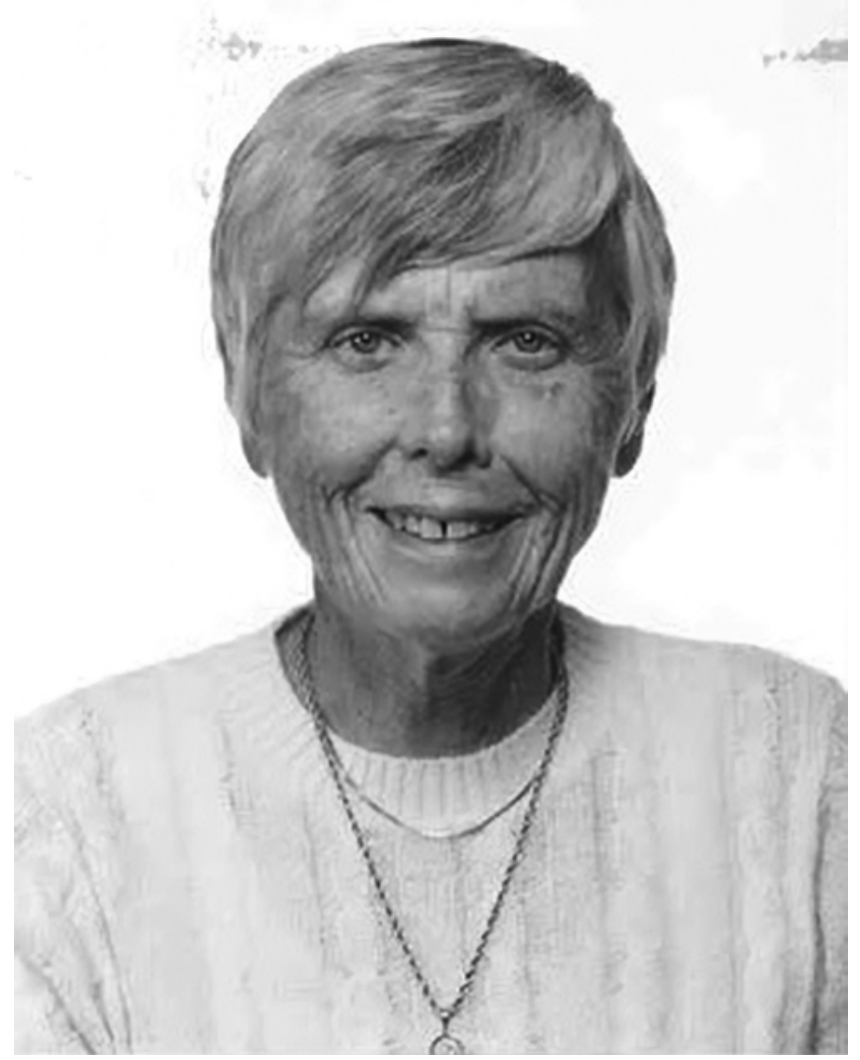

FIG. 3. Joan Venes, 2005. Copyright Chris Philips. Published with permission.

Renfrow and colleagues ${ }^{18}$ describe career trajectories of women neurosurgeons in the last 50 years. They demonstrate that more than a quarter of women pursued fellowship training and the majority ended up in private practice clinical settings. Additionally, women are severely underrepresented in leadership positions, with only 7 residency program directors, 5 fellowship program directors, and 3 vice chairs of neurosurgery departments. Women comprise only $15.5 \%$ of board/executive committee positions within the AANS, CNS, SNS, Council of State Neurosurgical Societies (CSNS), and ABNS.

Slowly but surely, the field of neurosurgery is changing; there is a growing recognition of the systemic barriers that exist for professional women in neurosurgery, fueling collective movements to address the glass ceiling and the leaky pipelines. In addition to WINS, the Association of Women Surgeons has advocated since 1981 for women throughout their careers in surgery. Recently, the Gender Equity Initiative in Global Surgery (GEIGS) at the Harvard Program in Global Surgery and Social Change (PGSSC) was formed to reduce gender disparities in the surgical workforce and empower women surgeons worldwide through research, advocacy, and mentorship. ${ }^{17}$ These organizations are stimulating the much-needed policy changes to bring about gender equity in the surgical workforce.

Breaking new ground, the women neurosurgeons of the profession's first 100 years have persisted, succeeded, and made their marks in the male-dominated field. They have recruited and encouraged younger women to join the field. Thanks to these trailblazing leaders, other bright women have gained entry and have excelled in the profession, advancing the field of neurosurgery in a multitude of directions over the past century. As we celebrate these exceptional neurosurgeons and their accomplishments, we must also recognize the barriers that they have had to overcome in pursuing neurosurgery as women. The past 30 years in particular have been a period of increasing involvement and responsibility for women in neurosurgery. This progress is a reflection of both the changing times in American society and the influence of organizations such as WINS. Notably, in 2020 we anticipate celebrating the 30th anniversary of WINS, and expect continued expansion and progress for the years to come. Looking forward to the next century, we must now focus on continual system improvements that will promote a diverse and excellent workforce toward a welcoming environment for all aspiring neurosurgeons, in order to advance the specialty in the service of neurosurgical patients.

\section{Acknowledgments}

We thank the following individuals whose experiences and insights have been critical to the progress of women in neurological surgery: Deborah Benzil, Karin Muraszko, and Edie Zusman. Chris Philips, AANS staff support for WINS for 30 years, has been a treasured friend and colleague for all members of WINS. Judy Rosman, Esq., President of RosmanSearch, Inc., has actively recruited women neurosurgeons for leadership positions.

\section{References}

1. Abosch A, Rutka JT: Women in neurosurgery: inequality redux. J Neurosurg 129:277-281, 2018

2. American Association of Neurological Surgeons (AANS): Frances K: Conley, MD. Women in Neurosurgery (WINS). Rolling Meadows, IL: AANS (http://www. neurosurgerywins.org/doctor/dr-frances-conley) [Accessed January 2, 2020]

3. Association of American Medical Colleges (AAMC): More Women Than Men Enrolled in U.S. Medical Schools in 2017. Washington, DC: AAMC (https://news.aamc.org/ press-releases/article/applicant-enrollment-2017/) [Accessed January 2, 2020]

4. Bean J: Women in neurosurgery. J Neurosurg 109:377-377, 2008

5. Benzil DL, Abosch A, Germano I, Gilmer H, Maraire JN, Muraszko K, et al: The future of neurosurgery: a white paper on the recruitment and retention of women in neurosurgery. $\mathbf{J}$ Neurosurg 109:378-386, 2008

6. Conley FK: Walking Out on the Boys. New York: Farrar, Straus \& Giroux, 1998

7. Corley J, Williamson T: Women in neurosurgery: final frontier of career women's movement. World Neurosurg 111:130-131, 2018

8. Davey LM: Louise Eisenhardt, M.D.: first editor of the Journal of Neurosurgery (1944-1965). J Neurosurg 80:342346, 1994

9. Dixon A, Silva NA, Sotayo A, Mazzola CA: Female medical student retention in neurosurgery: a multifaceted approach. World Neurosurg 122:245-251, 2019

10. The early accomplishments and engagement of Krystal Tomei, MD, MPH. AANS Neurosurgeon 27(1): 2018 (https://aansneurosurgeon.org/features/earlyaccomplishments-engagement-krystal-tomei-md-mph/) [Accessed January 2, 2020] 
11. Firlik K: Another Day in the Frontal Lobe: A Brain Surgeon Exposes Life on the Inside. New York: Random House, 2007

12. German WJ: Dr. Louise Eisenhardt. J Neurosurg 26:285288, 1967

13. Greenblatt SH, Dagi TF, Epstein MH (eds): A History of Neurosurgery: In Its Scientific and Professional Contexts. Park Ridge, IL: American Association of Neurological Surgeons, 1997

14. Massachusetts General Hospital: Find a Doctor: Maya Babu, MD, MBA. Boston: Massachusetts General Hospital (https://www.massgeneral.org/doctors/doctor.aspx?id=20498) [Accessed January 2, 2020]

15. McClelland S III: Alexa Irene Canady: the first AfricanAmerican woman neurosurgeon. J Natl Med Assoc 100:439-443, 2008

16. McClelland S III: M. Deborrah Hyde, MD, MS: the second African-American female neurosurgeon. J Natl Med Assoc 99:1193-1195, 2007

17. Program in Global Surgery and Social Change (PGSSC): Gender Equity in Global Surgery. Boston: PGSSC (https:// www.pgssc.org/gender-equity-global-surgery) [Accessed January 2, 2020]

18. Renfrow JJ, Rodriguez A, Wilson TA, Germano IM, Abosch A, Wolfe SQ: Tracking career paths of women in neurosurgery. Neurosurgery 82:576-582, 2018

19. Rosseau G, Apple S, Benzil DL, Germano I, Glick R, Muraszko K, et al: Walking out on the boys. J Neurosurg 92:738, 2000 (Letter)

20. Rosseau G, Johnson WD, Park KB, Arráez Sánchez M, Servadei F, Vaughan KA: Global neurosurgery: current and potential impact of neurosurgeons at the World Health Organization and the World Health Assembly. Executive summary of the World Federation of Neurosurgical Societies-World Health Organization Liaison Committee at the 71st World Health Assembly. Neurosurg Focus 45(4):E18, 2018

21. Ruth Kerr Jakoby, MD. Women in Neurosurgery (WINS) (http://www.neurosurgerywins.org/doctor/dr-ruth-jakoby) [Accessed January 2, 2020]

22. Ruth Kerr Jakoby, MD, FACS, JD, Interviewed by Gail Rosseau, MD (https://www.youtube.com/ watch?v=R1CQbARcIsA) [Accessed January 2, 2020]
23. Smith K: Faces of Neurosurgery: Kathryn Ko, MD. Neurosurgery Blog. February 24, 2017 (https://www. neurosurgeryblog.org/2017/02/24/faces-of-neurosurgerykathryn-ko-md/) [Accessed January 2, 2020]

24. Society of Neurological Surgeons (SNS): New Design. Schaumburg, IL: SNS (https://www.societyns.org/history/ history1.html) [Accessed January 2, 2020]

25. Spetzler RF: Progress of women in neurosurgery. Asian J Neurosurg 6:6-12, 2011

26. US National Library of Medicine: Carole Miller, MD [Biography]. Bethesda, MD: US National Library of Medicine (https://www.nlm.nih.gov/exhibition/locallegends/ Biographies/Miller_Carole.html) [Accessed January 2, 2020]

\section{Disclosures}

Dr. Sweet is on the Scientific Advisory Board for Koh Young, Inc.

\section{Author Contributions}

Conception and design: Corley, Kim, Parr, Rosseau. Acquisition of data: Corley, Kim, Rosseau. Analysis and interpretation of data: Sweet. Drafting the article: Corley, Parr, Sweet, Rosseau. Critically revising the article: all authors. Reviewed submitted version of manuscript: all authors. Approved the final version of the manuscript on behalf of all authors: Corley. Administrative/ technical/material support: all authors. Study supervision: Parr, Sweet, Rosseau. Providing historical facts and figures: Philips.

\section{Supplemental Information}

Online-Only Content

Supplemental material is available with the online version of the article.

Supplemental Table 1. https://thejns.org/doi/suppl/10.3171/ 2019.12.JNS192878.

\section{Correspondence}

Jacquelyn Corley: Duke University Hospital, Durham, NC. jacorley21@gmail.com. 